\title{
RETROSPECTIVE ANALYTICAL STUDY OF MEDICAL MALPRACTICE CASES AT QALYUBIA GOVERNORATE (2010-2014)
}

\author{
Asmaa Mahmoud Meghaoury, Ola Gaber Haggag, Rabab Fawzi Hindawi, Amina \\ A. Farag \\ Forensic medicine and Clinical Toxicology Department, Faculty of Medicine, Benha \\ University, Egypt
}

ola.hagag@fmed.bu.edu.eg

rabab.hindawy@fmed.bu.edu.eg

amina.farag@fmed.bu.edu.eg

\begin{abstract}
Background Medical malpractice suits represent a valuable source of information on medical errors. Therefore, a greater understanding of the claims may highlight their causes and thus help to prevent them. Aim: To evaluate the problem of medical malpractice and study the epidemiological and medicolegal aspects of the reported cases of medical malpractice at medico legal region of Benha, Qalyubia governorate from (2010 to 2014).Methods: Retrospective analysis of all medical malpractice claims, registered during the period of study (from January 2010 to December 2014) in Qalyubia governorate .Cases were reviewed from medico legal authority records. Results: Out of 113 malpractice claims, (55.8\%) were females, (37.2\%) of cases ended by death, $(20.4 \%)$ ended with permanent infirmity and $(42.5 \%)$ ended with other injuries. Most of the cases (58.4\%) were aged 18-40 years. More than half of the malpractices occurred in public hospitals $(59.3 \%)$, (31\%) in private hospitals and $(9.7 \%)$ in private clinics. $(69.9 \%)$ resulted from surgical interventions. Malpractice claims reported in gynecology and obstetrics $(31.9 \%)$ followed by general Surgery $(19.5 \%)$ then anesthesia (12.4\%), while pediatrics, dentist and vascular surgery had the least percentage $(0.9 \%)$.Conclusion: Although most of malpractice claims resulted in severe injuries, they are preventable. This indicates the great need for more effort to increase patient safety in all health care settings.
\end{abstract}

Key words: medical malpractice, Qalyubia governorate.

\section{INTRODUCTION}

Medical malpractice represents an unwelcome emotional and economic burden to the involved practitioners, patients, and patients' families, and it is a huge problem around the world (Fanggang et al., 2015).

Medical malpractice occurs due to defective treatment in the course of providing health service or professional negligence by act or omission by a health care provider in which care provided deviates from accepted standards of practice in the medical community and harms the patient (Yazıcı et al., 2015).

Medicine is changing as physicians are employed, quality and outcomes are routinely measured and health care finance is moving to value-based purchasing. The medical malpractice system needs to adapt to these forces that are reshaping health care (Mello et al., 2014).

The health care system must promote a culture of open 
communication between clinicians and patients that persists even after a patient has experienced a negative outcome allows for robust process improvement (Kass and Rose, 2016).

The various goals of malpractice reform are to ensure patient compensation, reduce physician burden, improve patient safety, and reduce defensive medicine and to reduce health care costs (Parekh and Hoagland, 2017).

The law does not determine a way of calculation for compensation for pain and suffering and the judge must take into consideration the medical opinion and calculate the scope of the suffering. The court ruling determined criteria that influence the sum of the compensation (Levin, 2017).

It is recommended that developing a culture of safety should become a priority for healthcare organizations to help in preventing and reducing errors and improve overall healthcare quality for patients (Pimentel et al., 2017).

\section{AIM OF THE WORK}

The present work will be conducted to evaluate the problem of medical malpractice and study the demographic and medico-legal aspects of the reported cases of medical malpractice at medico-legal region of Benha, Qalyubia governorate.

\section{MATERIAL \& METHODS}

This is a retrospective statistical study that was carried out on all alleged malpractice cases in Qalyubia governorate during the period from
January 2010 to December 2014, at medicolegal region of Benha, Ministry of Justice, Egypt. The study was authorized and approved by the local research ethics committee of Benha faculty of medicine, Benha University, and also by the authority of forensic medicine. The following data was studied:

I. Demographic data: age, gender, residence

II. Medico-legal analysis: medical specialty, type of health center, type of medical malpractice, stage of treatment at which medical malpractice occurred, the outcome of medical malpractice, Approval of malpractice claims according to opinion of forensic medicine specialist.

\section{Statistical design:}

The collected data will be tabulated and statistically analyzed using SPSS version 17 microstate software package (SPSS Inc, Chicago, ILL Company).

- ANOVA test (F value).

- Chi square test ( $\mathrm{X}^{2}$-value).

- Fisher Exact Test (FET).

The accepted level of significance in this work was stated at $0.05(\mathrm{P}<0.05$ was considered significant).

\section{RESULTS}

The present study showed that the total number of malpractice claims was (113) cases that recorded in archived reports on which medico-legal examination and autopsies were conducted at medico legal region of Benha during the period of study (from January 2010 to December 2014). 
Table (1): Frequency of malpractice claims and type of malpractice according to years.

\begin{tabular}{|c|c|c|c|c|c|c|}
\hline Type of malpractice & $\mathrm{Neg}$ & sence & Me & error & FET & P value \\
\hline Year & No & $\%$ & No & $\%$ & \multirow{7}{*}{$1.36^{\wedge}$} & \multirow{7}{*}{ ) $0.87 \mathrm{NS}($} \\
\hline 2010 & 14 & 63.6 & 8 & 36.4 & & \\
\hline 2011 & 15 & 65.2 & 8 & 34.8 & & \\
\hline 2012 & 10 & 71.4 & 4 & 28.6 & & \\
\hline 2013 & 24 & 55.8 & 19 & 44.2 & & \\
\hline 2014 & 7 & 63.6 & 4 & 36.4 & & \\
\hline Total & 70 & 100 & 43 & 100 & & \\
\hline
\end{tabular}

The distribution of the studied 2012, 43 cases in 2013 and 11 cases in cases of malpractice claims through the 2014. Most of cases were presented period of the study was 22 cases in with medical negligence (70) cases out 2010, 23 cases in 2011, 14 cases in of 113 cases.

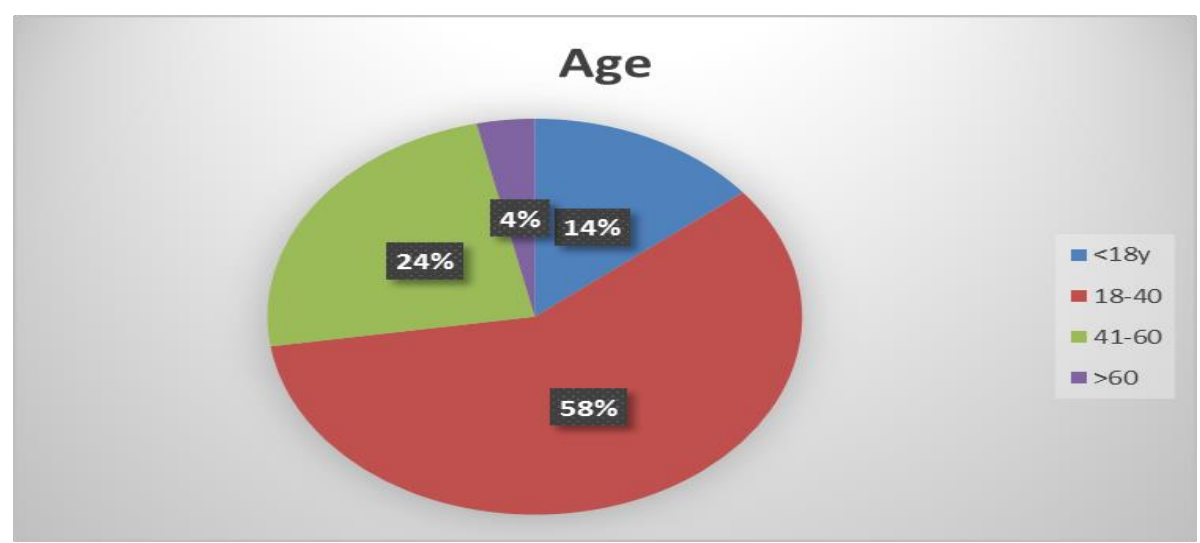

Figure (1): Age groups and age distribution in each group in the studied cases.

The age of the studied cases ranged between (1-70 years) with mean age of $(32.8 \pm 15.92)$. The age group of adults
(18-40 years) represented the highest percentage $(58.4 \%)$.

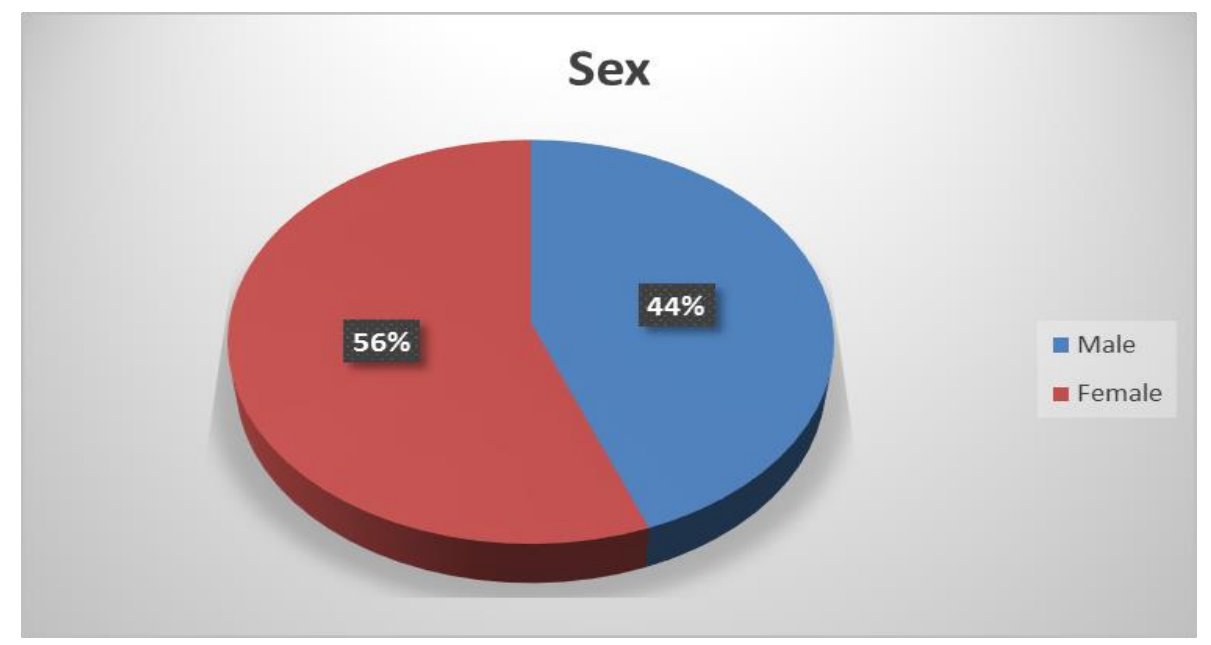

Figure (2): Sex distribution in the studied cases.

Females represented higher percentage $(55.8 \%)$ of the studied cases than males. 


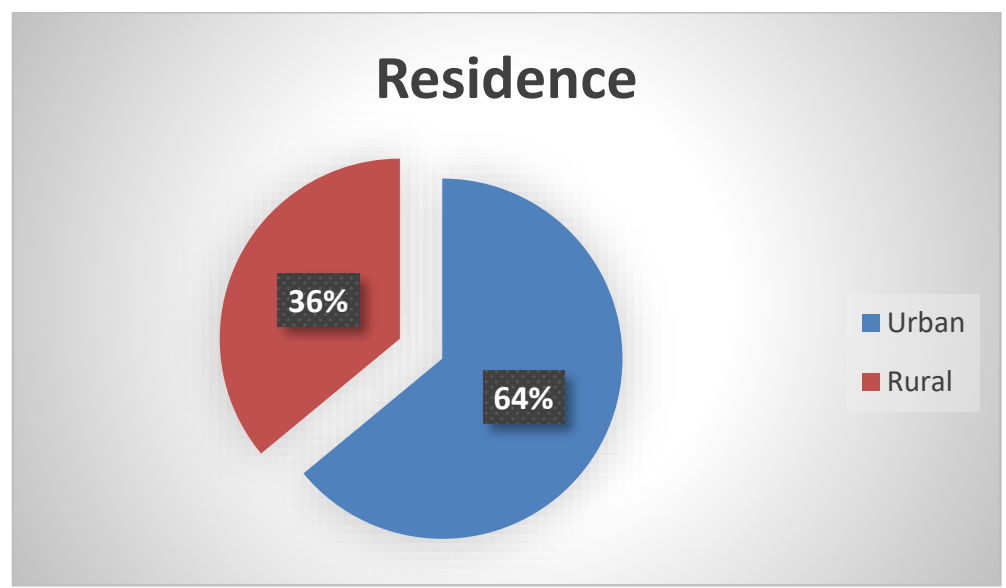

Figure (3): Distribution of the studied cases according to the residence.

The higher percentage of the studied cases lived in urban areas (63.7
$\%)$, while only (36.3\%) of the cases were from rural areas.

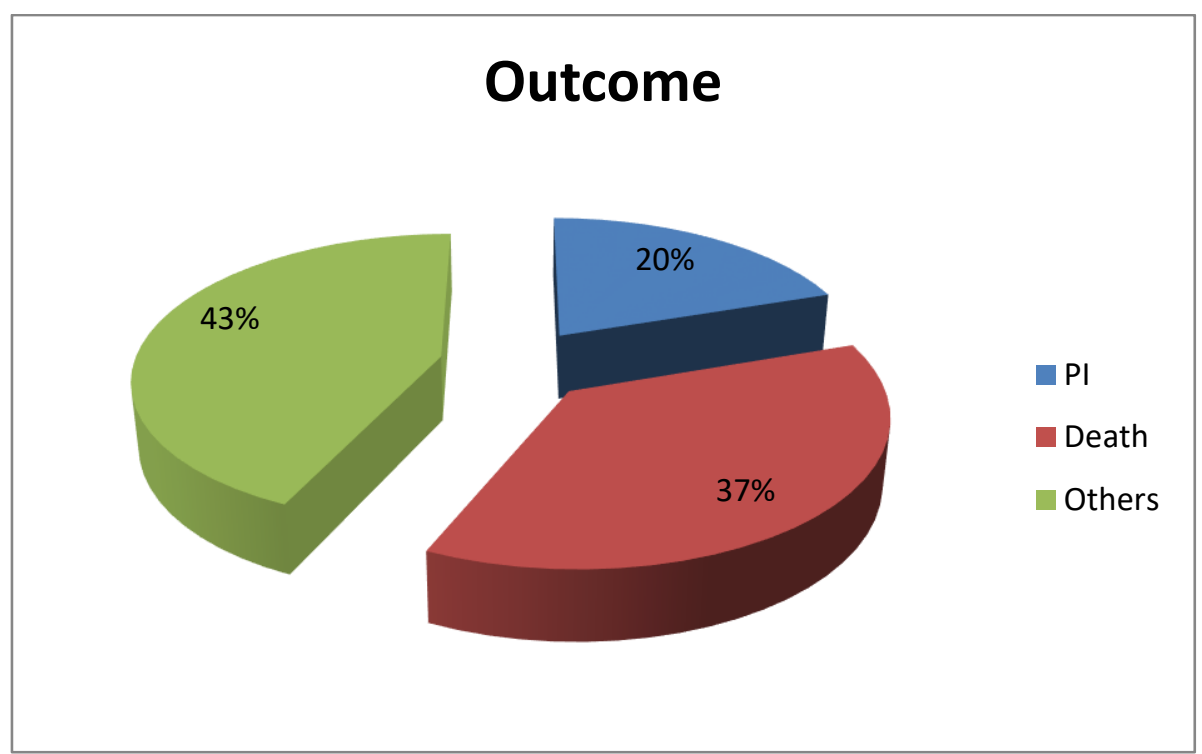

Figure (4): Malpractice outcome among the studied cases.

Regarding the outcome of the studied cases, this study demonstrated that $(37.2 \%)$ of cases ended with death, permanent infirmity (PI) in $(20.3 \%)$ of cases while other injuries rather than death and permanent infirmity represented the highest percentage $(42.5 \%)$. 


\section{Approval of malpractice cases according to opinion of forensic medicine specialist}

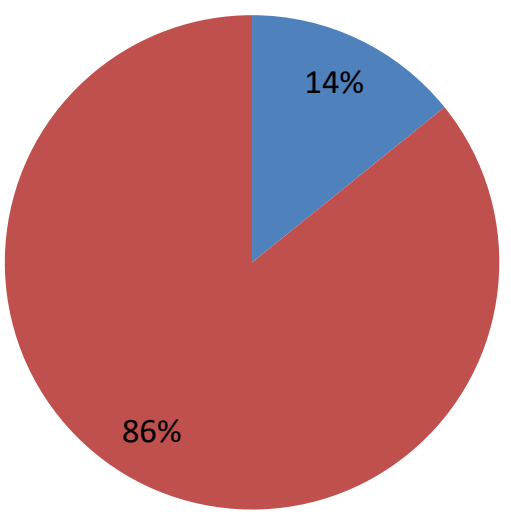

Confirmed

Non confirmed

Figure (5): Approval of malpractice claims regarding forensic medicine specialist opinion.

The present study showed that malpractice claims were non confirmed in $(85.8 \%)$ of cases, however there were few confirmed cases about (14.2 $\%)$.

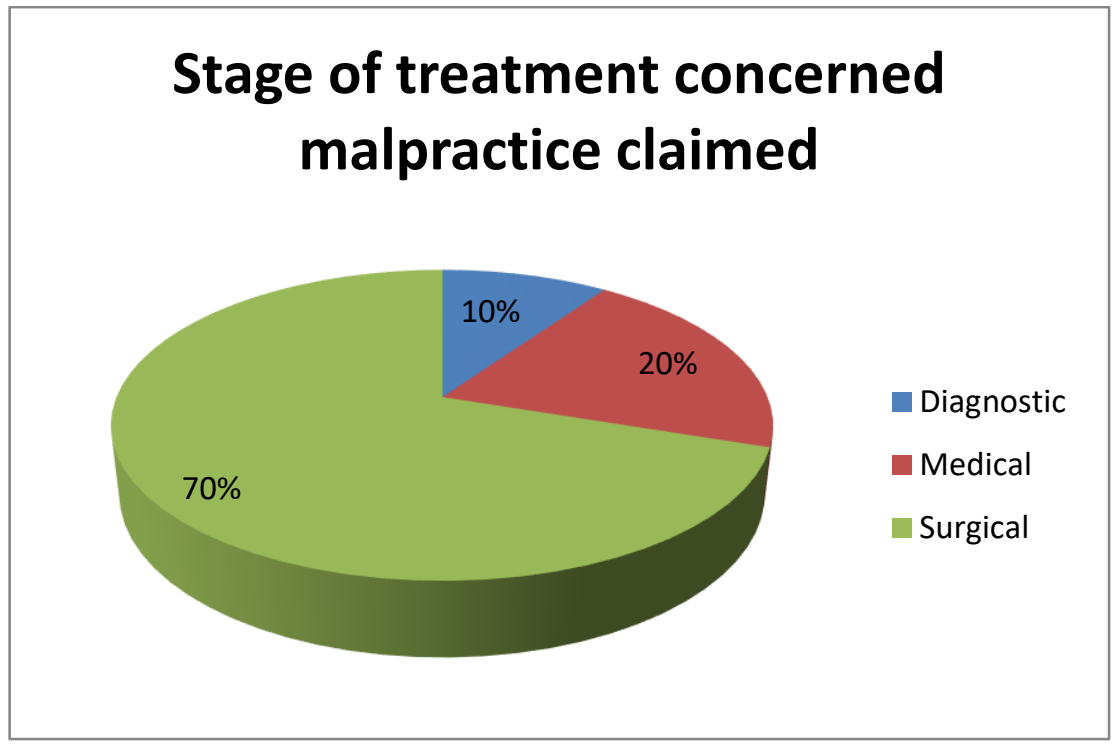

Figure (6): Stage of treatment concerned malpractice claims.

Regarding stage of treatment at which malpractice had occurred, this study found that surgical stage constituted the highest percentage
(69.9\%) followed by medical stage $(20.4 \%)$ then diagnostic stage constituted the least percentage $(9.7 \%)$. 


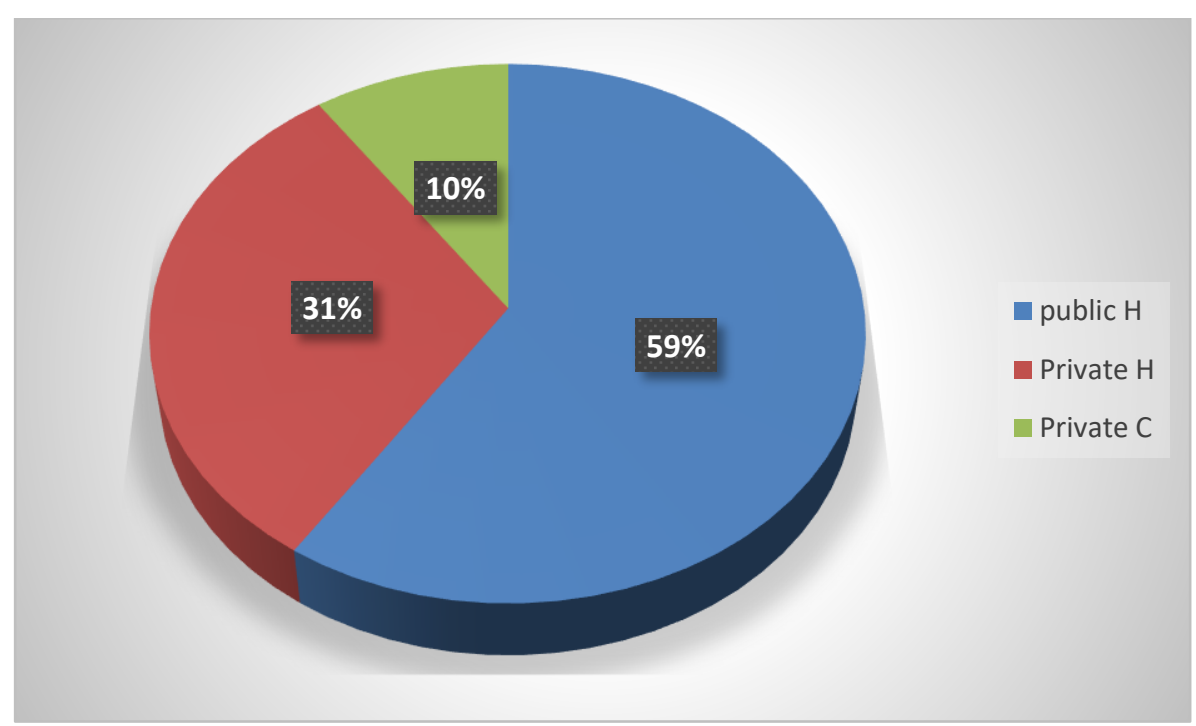

Figure (7): Malpractice cases among health care centers

The present study found that public hospitals had the highest percentage of malpractice claims $(59.3 \%)$ ) followed by private hospitals $(31.0 \%)$ while private clinics had the least percentage of claims $(9.7 \%)$.

Table (2): Frequency of malpractice claims according to medical specialty

\begin{tabular}{|c|c|c|}
\hline Medical specialty & No & \% \\
\hline Anesthesia & 14 & 12.4 \\
ENT & 4 & 3.5 \\
General surgery & 22 & 19.5 \\
Internal medicine & 3 & 2.7 \\
Neuro surgery & 9 & 8.0 \\
Gynecology and obstetrics & 36 & 31.9 \\
Oncology & 2 & 1.8 \\
Ophthalmology & 5 & 4.4 \\
Orthopedic surgery & 12 & 10.6 \\
Pediatrics & 1 & 0.9 \\
Urology & 3 & 2.7 \\
Vascular surgery & 1 & 0.9 \\
Dentistry & 1 & 0.9 \\
\hline Total & $\mathbf{1 1 3}$ & $\mathbf{1 0 0}$ \\
\hline
\end{tabular}

Regarding medical specialty, this study illustrated that obstetrics and gynecology had the highest percentage (31.9\%),three quarters of these cases (27 out of 36 case) belong more to labor ( obstetrics ). General surgery represented (19.5\%) then anesthesia $(12.4 \%)$, while pediatrics, dentistry and vascular surgery had the least percentage $(0.9 \%)$. 


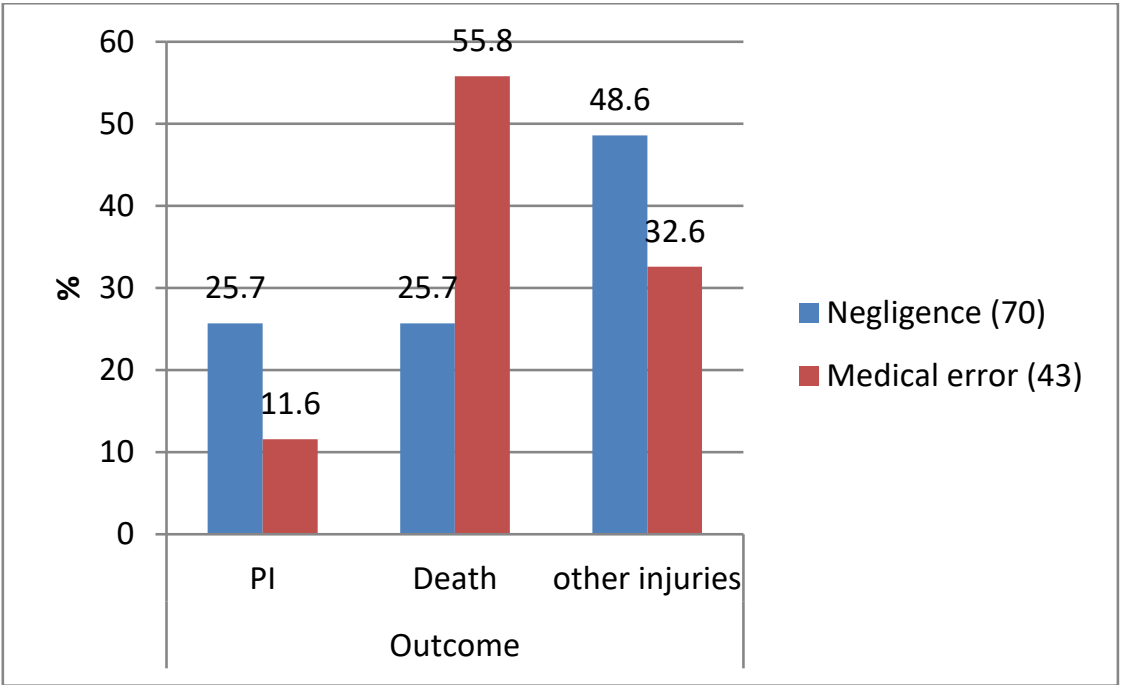

Figure (8): Relation between malpractice type and patient outcome.

The present study showed that there was statistically significant relation between the type of malpractice and outcome among the studied cases. Permanent infirmity (PI) was higher with medical negligence (25.7\%), death was higher with medical errors $(55.8 \%)$, and other injuries occurred more with negligence (48.6\%).

Table (3): Type of health center differences among the studied cases.

\begin{tabular}{|c|c|c|c|c|c|}
\hline & $\begin{array}{l}\text { Public } \\
\text { Hospital (67) }\end{array}$ & $\begin{array}{l}\text { Private } \\
\text { hospital (35) }\end{array}$ & $\begin{array}{l}\text { Private clinic } \\
\text { (11) }\end{array}$ & FET & P value \\
\hline $\begin{array}{l}\text { Age } \\
\text { Mean } \pm \text { SD }\end{array}$ & $33.62 \pm 15.99$ & $35.43 \pm 14.3$ & $19.45 \pm 15.15$ & $\mathrm{~F}=4.73$ & $0.011(\mathrm{~S})^{*}$ \\
\hline $\begin{array}{l}\text { Type of } \\
\text { malpractice } \\
\text { Negligence } \\
\text { Medical error } \\
\end{array}$ & $\begin{array}{l}36(53.7 \%) \\
31(46.3 \%)\end{array}$ & $\begin{array}{l}29(82.9 \%) \\
6(17.1 \%)\end{array}$ & $\begin{array}{l}5(45.5 \%) \\
6(54.5 \%)\end{array}$ & 10.08 & $0.005^{* *}(\mathrm{~S})$ \\
\hline $\begin{array}{l}\text { Stage of } \\
\text { treatment } \\
\text { Diagnostic } \\
\text { Medical } \\
\text { Surgical }\end{array}$ & $\begin{array}{l}7(9.1 \%) \\
20(30.3 \%) \\
40(60.6 \%)\end{array}$ & $\begin{array}{l}1(2.9 \%) \\
1(2.9 \%) \\
33(94.3)\end{array}$ & $\begin{array}{l}3(27.3 \%) \\
2(18.2 \%) \\
6(54.5 \%)\end{array}$ & 18.35 & $0.001 * *(\mathrm{~S})$ \\
\hline $\begin{array}{l}\text { Malpractice } \\
\text { outcome } \\
\text { PI } \\
\text { Death } \\
\text { Other injuries }\end{array}$ & $\begin{array}{l}13(18.2 \%) \\
29(43.9 \%) \\
25(37.9 \%)\end{array}$ & $\begin{array}{l}8(22.9 \%) \\
12(34.3 \%) \\
15(42.9 \%)\end{array}$ & $\begin{array}{l}2(18.2 \%) \\
1(9.1 \%) \\
8(72.7 \%)\end{array}$ & 5.97 & 0.19 \\
\hline
\end{tabular}

There was significant difference between public hospitals, private hospitals and private clinics regarding age, type of malpractice, Stage of treatment and outcome. The highest percentage of cases receiving treatment in private hospitals was suspected to medical negligence.

Table (4): Relation between medical specialty and approval of malpractice claims. 


\begin{tabular}{|l|l|l|l|l|l|l|}
\hline \multirow{2}{*}{ Approval of claims } & \multicolumn{2}{l}{ Non confirmed } & \multicolumn{2}{l|}{ Confirmed } & \multirow{2}{*}{ FET } & \multirow{2}{*}{ P value } \\
\cline { 2 - 5 } Medical specialty & No & $\%$ & No & $\%$ & & \\
\hline Gynecology and obstetrics & 32 & 33.0 & 4 & 25.0 & & \multirow{2}{*}{$0.103(\mathrm{NS})$} \\
\hline General surgery & 19 & 19.6 & 3 & 18.8 & & \\
\cline { 1 - 5 } Anesthesia & 14 & 14.4 & 0 & 0.0 & \multirow{2}{*}{8.22} & \\
\hline Orthopedic surgery & 9 & 9.3 & 3 & 18.8 & \\
\hline Neurosurgery & 9 & 9.3 & 0 & 0.0 & \\
\hline Others & 14 & 14.4 & 6 & 37.5 & & \\
\hline Total & 97 & 100 & 16 & 100 & & \\
\hline
\end{tabular}

Others include: ENT, Internal medicine, ophthalmology, oncology, pediatrics, urology, vascular surgery and dentistry

The present work showed that the relation between medical specialty and approval of malpractice claims was statistically insignificant. The highest percentage of non-confirmed claims was in gynecology and obstetrics (33\%) and general surgery (32\%), while the highest percentage of confirmed claims was correlated with other specialties $(37.5 \%)$.

\section{DISCUSSION}

Over the past decade, there has been a steady increase in the number of malpractice litigations brought against healthcare providers. This was explained by an increase in the patients' awareness with regard to their rights in a setting of an overburdened health system with limited resources (Azab, 2013).

The present study showed that 2010 had 22 malpractice claims, 2011 had 23 claims, 2012 had 14 claims .It also found that 2013 had the highest number of claims (43cases), while 2014 had the least number of claims (11 cases).

The analysis of this study showed an increasing trend of medical negligence and error reporting from 2010 to 2013. This can be explained on the basis that more and more number of patients are becoming aware of the standards of medical care and demanding redressal (Samarkandi, 2006).

There was a noticed decrease in the number of cases in 2012 and 2014, this can be explained by that most of cases in 2012 still opened and final decision was taken in 2013, also during this period (2011\& 2012) in Egypt there was lack of good recording and documentation of claims due to political causes $\left(25^{\text {th }}\right.$ January revolution) with some sort of anarchy, while in 2104 there was number of cases still opened and not terminated so they were excluded in the collected data.

According to age groups in the present study, the largest number of malpractice claims was among age group $18-40$ years $(58.4 \%)$.

These results are consistent with the previous observation of Hassan et al., 2014 who demonstrated that the majority of patients was younger than 45 years (165 out of 243) cases.

In contrast Madea and Preu, 2009 indicated in their study in Germany that, the majority of patients were older than 50 years.

The high number of claims in this age can be explained by that females had the higher percentage of malpractice claims and most of them are at reproductive age $(2 \mathrm{nd}, 3 \mathrm{rd}$ and 
4th decade) which correlated to the highest percentage of malpractice claims in obstetrics\& gynecology specialty (Manar, 2014)

It is evident from the present study that females malpractice claims were dominant $(55.8 \%)$ of the studied cases.

The result of this study was in line with the study of Gogos et al., 2011 in China from 1998 to 2011 which found that, $69 \%$ of the plaintiffs were females and that, $31 \%$ of them were male patients, respectively.

The results in this study disagreed with a study conducted by Mwaheb, 2016 in Fayoum Governorate, Egypt, which showed that $50.9 \%$ of the study group were males and $49.1 \%$ were females.

These high percentage observed in females was correlated with obstetrics and gynecology malpractice claims which had the highest frequency of malpractice claims (Manar, 2014).

In the present study, it was found that malpractice claims were more common in urban areas $(63.7 \%)$ than rural areas $(36.3 \%)$.

These findings are supported by Hassan et al., 2014 who stated that regarding the locations of the events of malpractice claims, urban areas were more frequent than rural areas.

This is explained by that malpractice trends point to urbanization as contributing factor to more litigation. The relationship between local doctors and patients in rural areas may have limited the number of suits, while patients in growing urban centers, who often lacked long-term relationships with doctors, may have felt less restraint in suing (Brown, 2017).

Regarding the outcome of the studied cases, this study demonstrated that $(37.2 \%)$ of cases ended with death, permanent infirmity in $(20.3 \%)$ of cases while other injuries rather than death and permeant infirmity represented the highest percentage $(42.5 \%)$.

These results are, to some extent, in agreement with the data obtained by Landro, 2012 who demonstrated that, in the 9,744 cases identified between 1990 and 2010, just over 59.2\% suffered temporary injuries, $32.9 \%$ had permanent injury and $6 \%$ of patients died.

These results disagreed with Azab, 2013 who said that regarding cases outcomes, death was the most frequent outcome ( $42 \%$ of the cases), followed by severe injuries ( $21 \%$ of the cases).

Estimates of deaths caused by medical negligence is low due to under reporting of negligent acts and disputes related to negligence and contributed to death (Paula et al., 2011).

The present study showed that malpractice claims were not confirmed in $(85.8 \%)$ of cases, however there were few confirmed cases about (14.2 $\%)$.

These results are consistent with the previous observation of Madea and Preu, 2009 who demonstrated that, the percentage of approved medical malpractice $10 \%$ of all cases (446 of 4550).

On the other hand Selbst et al., 2005 study demonstrated that, physicians were held responsible for two-thirds of malpractice claims that were approved.

This can be explained by that malpractice litigation system is usually slow, tedious, expensive, frustrating for patients and negates any impact on deterring poor physician behaviors or on improving patient outcomes. Also there is an atmosphere of "deny and defend" in which patients' questions often unanswered, medical errors often 
unrecognized, and patient safety is not addressed (Jason et al., 2016).

Regarding stage of treatment at which malpractice had occurred, this study confirmed that surgical stage constituted the highest percentage $(69.9 \%)$ followed by medical stage $(20.4 \%)$ then diagnostic stage constituted the least percentage $(9.7 \%)$.

A study by Perrotti et al., 2006 found similar results to this study, that allegations bringing claim in decreasing order of frequency were surgical mishap (159 claims), improper treatment (42), failure to diagnose (40) and others (10).

On the other hand, the results of the present study disagreed with the study of Ozdemir et al., 2009 who reported that more than half of the malpractices resulted from non-surgical interventions $(58.7 \%)$.

This can be explained by endless situations that give rise to allegations of negligence in general surgery e.g. delayed diagnosis of acute abdomen , retention of instruments and swaps in operation sites, operation on the wrong patient, operation on the wrong limb, digit, or even organ, Failed vasectomy, without warning of subsequent sterility, and diathermy burns (Shephered, 2003).

The present study found that public hospitals had the highest percentage of malpractice claims $(59.3 \%)$ ) followed by private hospitals $(31.0 \%)$ while private clinics had the least percentage of claims $(9.7 \%)$.

These results are consistent with a study conducted by Mwaheb, 2016 which showed that the majority of malpractices occurred in general hospitals $(67.3 \%)$, more than in private clinics and hospitals.

It is thought that the higher percentage at government hospitals is because of the larger number of patients admitted to these hospitals in addition to the fact that there are more government hospitals than the other health facilities and that they are available in more areas of the country and most of them are less equipped (Manar, 2014).

On the contrary, Gogos et al., 2011 found that, Three-quarters of the incidents that prompted cases occurred in privately owned health care facilities and nearly two-thirds occurred in consulting rooms.

Regarding medical specialty, this study illustrated that obstetrics and gynecology had the highest percentage $(31.9 \%)$ followed by general surgery (19.5\%) then anesthesia (12.4\%), orthopedics $(10.6 \%)$ while pediatrics, dentist and vascular surgery had the least percentage $(0.9 \%)$.

These findings are supported by Teo, 2012 who stated that, Obstetrics and gynecology, general surgery and orthopedics are always the top three medical-risk specialties.

Obstetrics and gynecology has always had a reputation for being a highly litigious specialty as doctors are responsible for life of mothers and their babies and is usually surrounded by different circumstances that stimulate the doctors to practice defensive medicine (Ali et al., 2016).

On the contrary Ozdemir et al., 2009 found that, when the healthcare providers who performed the medical practices were evaluated, pediatricians took the lead among healthcare professionals accused of malpractice $(25.53 \%)$, followed by gynecologist and obstetrician $(19.74 \%)$, then general practitioners $(18.42 \%)$.

The present study showed that there was statistically significant relation between the type of malpractice and 
outcome among the studied cases. Permanent infirmity was higher with medical negligence $(25.7 \%)$, death was higher with medical errors $(55.8 \%)$, and other injuries occurred more with negligence $(48.6 \%)$.

On the other hand Manar, 2014 study found that regarding type of accusation and outcome of patient, $73.7 \%$ of malpractice death and $78 \%$ of permanent infirmity were due to medical negligence.

There is significant difference between public hospitals, private hospitals and private clinics regarding age, type of malpractice, Stage of treatment and outcome. The highest percentage of cases receiving treatment in private hospitals was suspected to medical negligence.

The present work showed that the relation between medical specialty and approval of malpractice claims was statistically insignificant. The highest percentage of non-confirmed claims was in gynecology and obstetrics (33\%) and general surgery (32\%), while the highest percentage of confirmed claims was correlated with other specialties (37.5\%).

On the other hand Manar, 2014 study found that there was no statistically significant relation between medical specialty and approval of malpractice claims.

\section{CONCLUSION}

The current study revealed some aspects of malpractice problem in Qalyubia governorate from 2010 2014 and demonstrated that 2013 had the highest percentage of confirmed malpractice claims.

The present study showed that, females had higher percentage of malpractice claim $(55.8 \%)$ most of them at reproductive age $(3 \mathrm{rd}$, 4 th and 5 th decade).

There is increase in surgical malpractice claims $(69.9 \%)$ within total medical malpractice cases.

This study found that public hospitals had the highest malpractice claims.

The outcome of malpractice among the studied cases in this study revealed that other injuries rather than death and permanent infirmity had the highest percentage $(42.5 \%)$.

\section{RECOMMENDATION}

Establishing mandatory and voluntary medical error reporting systems, to correct problems underlying these errors and patient safety can be improved.

It is essential to develop a strong health care system with the ability to accredit, monitor and evaluate the provided health services and the documentation system is required.

It is important to enact and enforce legal restrictions and regulatory controls and to raise public awareness of consumer rights and standard clinical behaviors.

\section{REFERENCES}

Ali A A, Hummeida ME, Wisal O, et al. (2016): Concept of defensive medicine and litigation among Sudanese doctors working in obstetrics and gynecology, BMC Med Ethics, 17: 12.

Azab S. (2013): Claims of malpractice investigated by the Committee of medical ethics, Egyptian medical syndicate, Cairo, Egyptian Journal of Forensic Sciences, 3(4):104-111.

Brown RB. (2017): Canada's first malpractice crisis: Medical negligence in the late nineteenth 
century. J Osgoode Hall Law, 54(3):794.

Fanggang H E, Liliang L I, Bynum J, et al. (2015): Medical malpractice in Wuhan, China: a10year autopsy-based single-center study, 94 (45):20 26.

Gogos A J, Clark R B, Bismark MM, et al. (2011): When informed consent goes poorly: a descriptive study of medical negligence claims and patient complaints, MJA, 195(6): 340-344.

Hassan DA, Shehab A M and Kotb H. (2014): Alleged medical malpractice: A retrospective study of forensic evaluation of cases in Cairo and Giza regions -Egyp (2009-2011). Forensic Res J 2014; 5(5): 239.

Jason A, Karen A, Ke nneth E, et al. (2016): Medical malpractice: reform for today's patients and clinicians, the American journal of medicine, 129 (1): 20-25.

Kass J S and Rose R V. (2016): Policy Forum. Medical malpractice reform historical approaches, alternative models, communication and resolution programs; AMA Journal of Ethics, 18(3):299-310.

Landro L. (2012): Surgeons Make Thousands of Errors, the Wall street Journal. Cited in: http://online.wsj.com.

Levin N. (2017): Medical malpractice in Israel and the financial and non financial damage to the victim; Sociology and Anthropology, 5(3): 220-224.

Manar AA Ahmed. (2012): Retrospective Study of medical malpractice cases at Beni-Suef governorate from 2004 - 2013. Thesis of master degree in forensic medicine and clinical toxicology. Supervisors: Sherien S Ghalb,
Dalia A Hassan and Amr R Zaki, Beni-Suef university.

Madea B and Preu B J. (2009): Medical malpractice as reflected by the forensic evaluation of 4450 autopsies. Forensic Science International, 190 (1-3): 58-66.

Mello M, Boothman R, McDonald T, et al. (2014): Communication and Resolution Programs: the challenges and lessons learned from six early adopters. Health Affairs (Millwood), 33(1): 20-29.

Mwaheb M A. (2016): Screening of Alleged Medical Malpractice in Egypt (Fayoum Governorate). Forensic Res J, 7(5): 341.

Ozdemir M H, Ergonen T A and Can I O. (2009): Medical malpractice claims involving children, Forensic Science International, 191: 80-85.

Parekh A and Hoagland W. (2017): Medical Liability Reform in a New Political Environment, JAMA, 317(13):1311-1312.

Paula P, Pottinger I, Kordina N, et al. (2011): Iatrogenic death: A review of cases from 1990-2000 investigated at the Department of Forensic Medicine, Vienna, Wien Klin Wochenschr, 123(17-18):52630.

Perrotti M, Badger W, Michael E, et al. (2006): Medical Malpractice in Urology, 1985 to 2004: 469 Consecutive Cases Closed with Indemnity Payment, the journal of urology, 176:2154-2157.

Pimentel MPT, Choi S, Fiumara K, et al. (2017): Safety culture in the operating room:variability among perioperative healthcare workers, patient safety J, (00)00.

Samarkandi A. (2006): Status of medical liability claims in Saudi Arabia. Ann Saudi med, 26(2): 8791. 
Selbst SM, Friedman MJ and Singh SB. (2005): Epidemiology and etiology of malpractice lawsuits involving children in US emergency departments and urgent care centers, Pediatr. Emerg. Care, 21:165-169.

Shephered R. (2003): The ethics of medical practice and Medical Malpractice, In: Serena Bureau; Layla Vandebregh; and James Rabson, Simpson's forensic medicine; Ch2\&3. 12th edition, pp8-21.
Teo D. (2012): 7th International Association of Biological Standardization (IABS) Symposium on Advances in Transfusion Safety.Biologicals, 40:169.

Yazici YA, Sen H, Aliustaoglu S, et al. (2015): Evaluation of the medical malpractice cases concluded in the general assembly of council of forensic medicine, 21(3): 204 - 208. 
دراسة تحليلية مرجعية لحالات سوء الممارسة الطبية بمحافظة القليوبية خلال القترة من

]2014-2010[

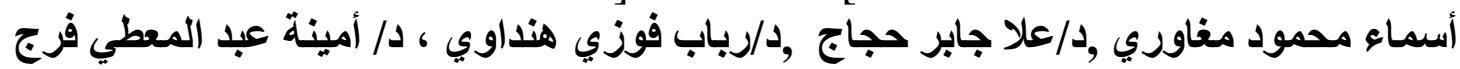

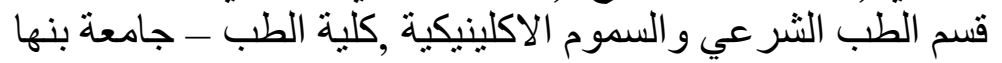

نبذه عن الموضوع : تمثل دعاوي سوء الممارسة الطبية مصدرا قيما للمعلومات عن الأخطاء

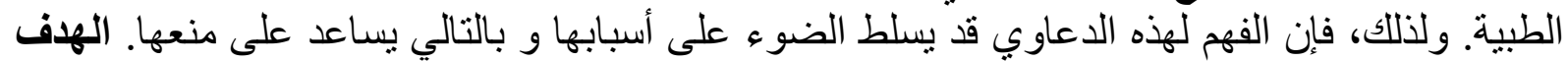

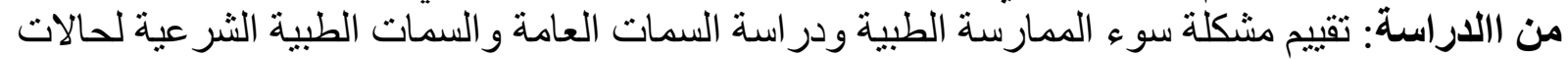
سوء الممارسة الطبية المبلغ عنها في المنطقة الطبية بمدينة بنها، محافظة القليوبية خلال القال الفترة من 2010

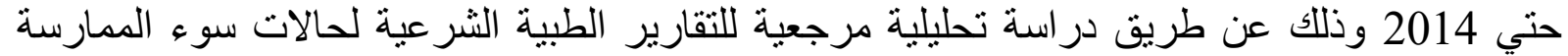

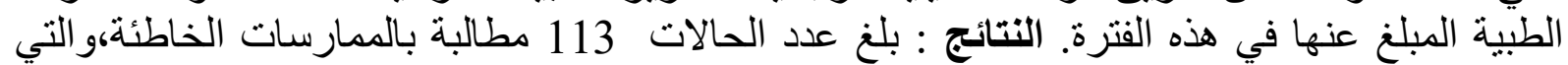

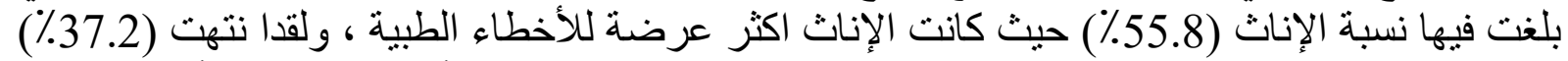

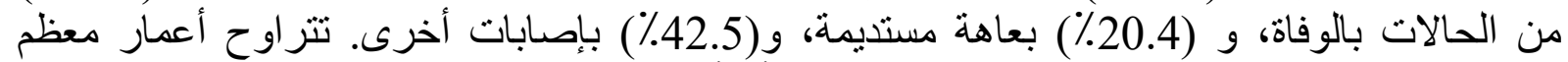

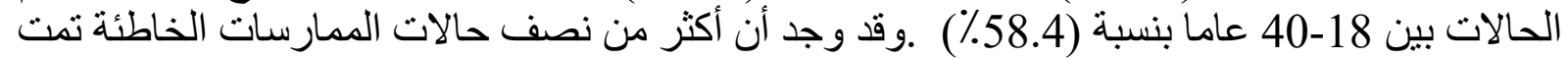

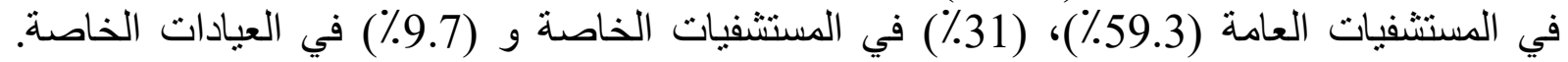

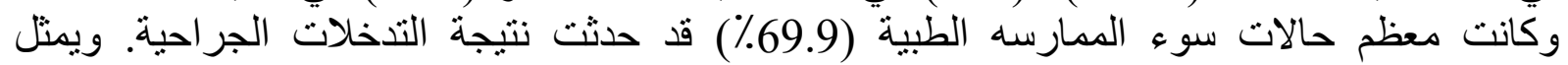
تخصص أمر اض النساء و التوليد أعلي نسبة في دعاوي الأخطاء الطبية (12\% 31.9) يليه الجر احة العامه

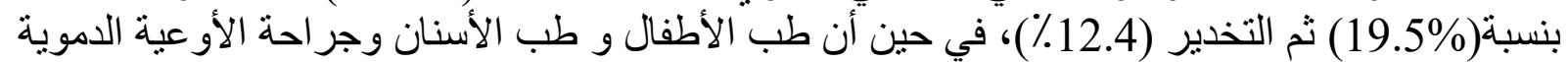

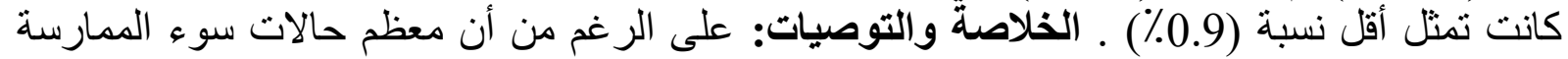

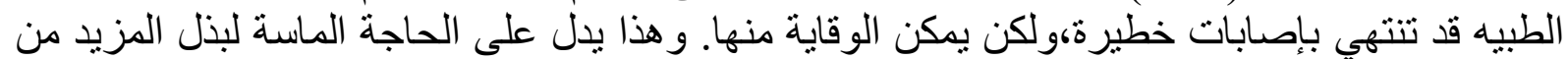
الجهد لزيادة سلامة المرضى في جميع در افق الر عاية الصحية. 